\title{
Numerical Simulation of Shock Wave Interaction with a Slab of Compressible Foam Attached to a Solid Wall
}

\author{
By \\ Ahmed A. Sileem \\ Mech. Power Eng. Dept., Faculty of Engineering \\ Menoufia University, Shebin El-Kom, Egypt
}

\begin{abstract}
:
Numerical simulation of normal shock wave interaction with a slab of compressible foam attached to a solid wall is the scope of the present work. The foam is modeled as solid particles suspended in air. Therefore, the foam is treated as two-phase medium of solid particles and air. The drag force and heat transfer between particles and air are taken into consideration. The influence of foam density, incident shock Mach number and foam slab length on the reflected and transmitted waves strength, on the flow field inside and outside the foam and also on the pressure at solid wall behind the foam are studied. The numerical results reflect all the salient features of the interaction process and its consequences. The results of the present numerical simulation are compared with experimental results of Skews [1991] and showed a satisfactory agreement. It is shown that the effect of increasing foam length is to delay the arrival of the transmitted wave to the solid wall and the maximum pressure at wall increases slightly. In addition, the rate of wall pressure increase is greater for smaller foam length. The increase in incident shock Mach number increases the wall pressure and the rate of increase is greater for greater incident Mach number. The pressure at the wall decreases after reflection to almost constant value in the used time span. This constant value increases with the increase in incident Mach number. The numerical results showed also that the delay in the arrival of transmitted wave to the solid wall is greater for greater foam density. The maximum pressure at the solid wall decreases with the increase of foam density, but it decays to almost constant value regardless of the foam density. The maximum pressure at wall with foam attached to it considerably exceeds
\end{abstract}

Manuscript received fromDr. Ahmed A.. Sileem

Accepted on : 31/12/2000

Engineering Research Journal Vol 24,No 2, 2001 Minufiya University, Faculty Of

Engineering, Shebien El-Kom , Egypt , ISSN 1110-1180 
the maximum pressure when no foam exists. The value of this pressure depends on the incident Mach number.

Key Words: Foam, two-phase flow, shock wave and numerical simulation.

\section{1-INTRODUCTION:}

Numerical simulation of weak shock wave interaction with a slab of compressible foam attached to a solid wall is the main objective of the present work. The interest in this problem stems from the need to suppress the effects of explosion waves and to protect structures and devices from hazards of explosions whenever they happen. Using compressible foam as a mean to attenuate shock and detonation waves attracted the attention of researchers in the last few decades because of its particular mechanical properties. (Monti [1970], Gelfand et al. [1975,1983], Kamel et al. [1984], Govezdeva et al. [1985], El-Mokkadem et al. [1989], Skews [1991, 1992] and Baer [1993] contributed in studying the foam as a mean of shock and detonation waves attenuation.

Monti [1970] reported theoretical and experimental study on the interaction between normal shock waves and deformable solid materials (closed and open cell foams). Theoretically, Monti predicted both the reflected wave into the gas and the transmitted wave into the foam. His experimental and theoretical results were in good agreement for incident shock Mach number in the range of $1.2<\mathrm{M}<2.2$.

Gelfand et al. [1975] showed experimentally that the maximum pressure recorded on the wall behind the foam is considerably larger than the normal reflection on the wall without foam. Gelfand [1983] modeled the foam as homogeneous pseudo-gas with adiabatic exponent and sound speed that depend on the ratio of mass of foam and gas and the volume fraction of solid phase in the mixture. This model predicted the reflected wave at the back wall as normal shock wave rather than compression wave recorded experimentally.

Govezdeva et al. [1985] measured the pressure on the wall with and without coating with foam. They found that the peak pressure on the wall in case of coating with foam is greater than that without coating. He concluded that the reflected pressure is strongly dependent on the mechanical properties of the material, the thickness of the layer and the incident shock Mach number.

In studying the damping capacity of foam, El-mokkadem et al. [1989] investigated experimentally the decay of detonation wave as it propagates in a slab of foam. They found that the detonation wave decays very rapidly when it propagates through the foam. The rate of decay was found to depend on the foam material density and its length. When the foam length increases enough, the detonation wave is completely extinguished. In their theoretical treatment they modeled the foam as two-phase medium in which the foam cells are filled with combustible mixture. They assumed also that the particles and the gas velocity and temperature are the same. 
of shock tube. He found that the reflected wave off the gas/foam interface is a normal shock and its strength is almost $80 \%$ of that reflected from rigid wall. $\mathrm{He}$ found also that the transmitted wave is reflected off the wall to propagate backward and then emerges from the foam/gas interface as compression wave of significant thickness. He reported also that the strength of these waves together is slightly higher than that reflected off rigid wall. A reduction in the strength of the shock reflected at the foam/gas interface and a substantial increase in the back wall pressure over that for rigid wall reflection were found. In a recent experimental study, Skews [1993] found an evidence of gas penetration through the foam skeleton. Skews noticed from photographs of the distortion of the foam that a compaction wave propagates through the foam material with lower velocity than that of the transmitted wave.

The modeling efforts to treat the foam as two-phase medium of solid particles suspended in air were reported by Gelfand et al. [1983], Kamel ét al. [1984] and El-Mokaddam et al. [1989]. In these studies the friction force and heat transfer between phases are neglected. Gelfand et al. [1983] showed that the wave reflected off the wall is a shock wave. Baer [1992] took into consideration the force and heat transfer exchange between phases in his numerical simulation of shock wave reflection of low density foam. To describe the rate of change of solid volume fraction, Baer used a compaction model derived by Baer et al. [1986]. His numerical results showed that the reflected wave from foam/gas interface; defined as first reflected wave (FRW); is normal shock and the reflected wave off the wall; defined as second reflected wave (SRW); is of compression type. Nonetheless, the incident shock wave (ISW) and FRW are not as sharp as that recorded by Skews [1991], rather it smeared considerably over a long period of time. The smearing of shock wave means that the used numerical method was not able to capture the shock wave accurately. His results showed the formation and propagation of compaction wave (CW) in the foam following the impact of the incident shock wave (ISW) on the foam. The increase in solid volume fraction was also noticed. Large pressure at wall behind the foam was found, as well. Sakakita et al. [1992] studied experimentally the interaction between propagating shock wave and a thin powder layer at the bottom end of vertical shock tube. His numerical simulation using models for drag force, heat transfer and compaction pressure, showed a sharp increase of pressure at the bottom wall but it is much lower than that he measured experimentally.

In a numerical simulation of EL-Mokkadem et al. [1989] experiment, Sileem [1998] modeled the foam as solid particles suspended in a stoichiometric mixture of acetylene and air. In that model the solid and gas phases are assumed to have the equal temperatures and velocities i.e., the interaction forces and heat transfer between solid and gas phases are neglected. The numerical results showed that when the detonation wave initially propagating in a homogenous reactive mixture hits the foam/gas interface a shock wave is reflected backward and the transmitted detonation wave decays sharply at the interface. A sudden reduction in the chemical heat release was noticed as a consequence of the sudden reduction in detonation speed. The 
results showed also that the attenuation increases with an increase in the solid volume fraction.

The review of literature showed that much effort still needed as far as modeling is concerned in order to get the best modeling of the shock wave interaction with foam slab attached to a solid wall. In addition, it is important to find out the most effective parameters that play significant roles in shock wave attenuation when foam is used as an attenuating material. Therefore, in the present work an attempt is made to simulate numerically, shock wave interaction with a slab of foam attached to the closed end of a tube. The foam is modeled as two-phase medium that consists of solid particles suspended in air. The momentum and energy transfer between phases is taken into consideration.

Different models for force exchange between phases have been used for different applications in two-phase flow of gas and solid particles. Baer [1992] used a correlation obtained by Shephered and Begeal [1983] as determined from experimental results of shock-induced high speed flow in porous shock tube. On the other hand, Sakakita et al. [1992] used Ergun [Bird et al. 1960] and Henderson [1986] type of drag coefficients in their numerical study on interaction between shock wave and a powder layer. It is noticed that the model used by Baer is very complex and that used by Sakakita is applied in case of high value of solid volume fraction.

The proposed model for force exchange between phases is a modified version of Ergun model, Bird et al. [1960] of pressure drop in packed columns in which the volume fraction of solid particles was large and the particle velocity was neglected. In contrast, the present model takes into consideration the drag force due to the relative motion between gas and solid phases. The relative motion is important since the volume fraction of solid phase in the mixture is very small. The model of drag force and heat transfer between phases used by Ibrahim [1983] and also by Ludwig et al. [1997] is adopted here. To verify the capability of the proposed models to simulate the shock wave interaction with a slab of foam attached to a solid wall, it was necessary to compare the present numerical simulation with the experimental results of Skews [1991].

The effects of incident shock Mach number, foam slab length and foam density on the strength of reflected wave to the gas and the transmitted wave (TW) through the foam and also on the pressure at the wall behind the foam are studied.

\section{2-MODELING}

It is assumed that a shock wave, of Mach number ranging from 1.2 to 1.35 , is propagating from left to right in a tube filled with air up to the face of foam slab attached to the closed end of the tube shown in Fig. 1. Therefore, the shock wave propagates in a homogeneous gas up to the face of the foam slab, then it propagates through the foam that is assumed to be two-phase medium of solid particles and air. 


\section{2-1. Assumptions:} equations:

The following assumptions are considered in deriving the governing

1-The gas phase is assumed to be an ideal gas with constant specific heats.

3-The solid particles are spherical, rigid and inert.

4-No phase change between solid particles and gas occurs.

5-The Eulerian formulation of the solid and gas phases is adopted.

6- Momentum and energy exchange between phases is allowed.

\section{2-2. Definitions:}

The volume fraction of the solid phase in the mixture is:

$$
\phi=\frac{V_{p}}{V}
$$

Where $V$ and $V_{p}$ are the volume of mixture and the volume occupied by particles, respectively.

The densities of gas and solid phases in the mixture are:

$\rho_{\mathrm{g}}=(1-\phi) \bar{\rho}_{\mathrm{g}}$

$\rho_{\mathrm{p}}=\phi \bar{\rho}_{\mathrm{p}}$

Where $\bar{\rho}_{\mathrm{g}}$ and $\bar{\rho}_{\mathrm{p}}$ are the material densities of gas and solid, respectively.

The material density of foam solid particles is calculated from the following equation:

$\bar{\rho}_{\mathrm{p}}=\frac{\rho_{\mathrm{f}}-\bar{\rho}_{\mathrm{g}}(1-\phi)}{\phi}$

The foam density $\left(\rho_{f}\right)$ for different foam types are shown in table I. The initial value of $\phi$ was measured by Skews [1991] for all of these types were found to be almost 0.05 even though their densities are different.

The material density of gas phase (air) is found from the gas equation of state, given the initial gas pressure and temperature $(83 \mathrm{kPa}$ and $300 \mathrm{~K})$;

$\mathrm{p}_{\mathrm{g}}=\bar{\rho}_{\mathrm{g}} \mathrm{RT} \mathrm{T}_{\mathrm{g}}$

Table I: The used foam densities

\begin{tabular}{cc} 
Material & Density $\left(\mathbf{k g} / \mathbf{m}^{\mathbf{3}}\right)$ \\
\hline Polyether (A) & 14.8 \\
Polyether (B) & 18.7 \\
Polyether (C) & 32.5 \\
Polyester (D) & 35.0 \\
Polyester (E) & 38.0
\end{tabular}




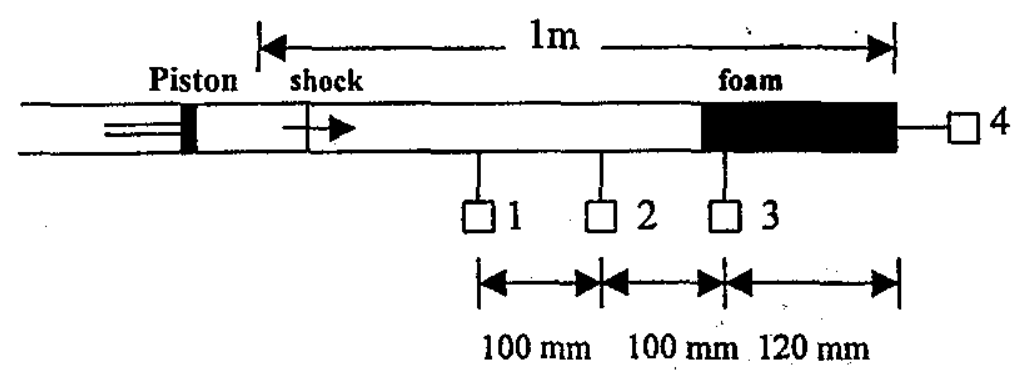

Fig. (1) The tube and location of pressure records.

\section{2-3.The governing equations:}

The equations governing the one-dimensional unsteady two-phase flow, Ludwig et al. [1997], are written below in semi-conservative forms. The interaction force and heat transfer between the solid and gas phases are taken into arcount. Nonetheless, up to the gas/foam interface, the solid phase parameters are given zero values.

The continuity, momentum and energy equations of the gas phase are:

$$
\begin{aligned}
& \left(\rho_{\mathrm{g}}\right)_{\mathrm{t}}+\left(\rho_{\mathrm{g}} \mathrm{u}_{\mathrm{g}}\right)_{\mathrm{x}}=0 \\
& {\left[\mathrm{u}_{\mathrm{g}} \rho_{\mathrm{g}}\right]_{\mathrm{t}}+\left[\rho_{\mathrm{g}} \mathrm{u}_{\mathrm{g}}{ }^{2}+(1-\phi) \mathrm{p}_{\mathrm{g}}\right]_{\mathrm{x}}=-\mathrm{F}} \\
& {\left[\mathrm{E}_{\mathrm{g}}\right]_{\mathrm{t}}+\left[\left(\mathrm{E}_{\mathrm{g}}+(1-\phi) \mathrm{p}_{\mathrm{g}}\right) \mathrm{u}_{\mathrm{g}}\right]_{\mathrm{x}}=-\left(\mathrm{Fu}_{\mathrm{p}}+\mathrm{q}\right)}
\end{aligned}
$$

The continuity, momentum and energy equations of the solid phase are:

$$
\begin{aligned}
& \left(\rho_{\mathrm{p}}\right)_{\mathrm{t}}+\left(\rho_{\mathrm{p}} \mathrm{u}_{\mathrm{p}}\right)_{\mathrm{x}}=0 \\
& {\left[\mathrm{u}_{\mathrm{p}} \rho_{\mathrm{p}}\right]_{\mathrm{t}}+\left[\rho_{\mathrm{p}} \mathrm{u}_{\mathrm{p}}{ }^{2}+\phi \mathrm{p}_{\mathrm{g}}\right]_{\mathrm{x}}=\mathrm{F}} \\
& {\left[\mathrm{E}_{\mathrm{p}}\right]_{\mathrm{t}}+\left[\left(\mathrm{E}_{\mathrm{p}}+\phi \mathrm{p}_{\mathrm{g}}\right) \mathrm{u}_{\mathrm{p}}\right]_{\mathrm{x}}=\left(\mathrm{Fu}_{\mathrm{p}}+\mathrm{q}\right)}
\end{aligned}
$$

The subscripts $\mathrm{x}$ and $\mathrm{t}$ refer to derivatives with respect to space and time, respectively.

The equation of state of the gas phase is:

$$
\mathrm{p}_{\mathrm{g}}=\rho_{\mathrm{g}} \mathrm{RT}_{\mathrm{g}} /(1-\phi)
$$

The energy of gas and solid phases are;

$$
\mathrm{E}_{\mathrm{g}}=\rho_{\mathrm{g}}\left(\mathrm{C}_{\mathrm{v}} \mathrm{T}_{\mathrm{g}}+\mathrm{u}_{\mathrm{g}}{ }^{2} / 2\right), \quad \mathrm{E}_{\mathrm{p}}=\rho_{\mathrm{p}}\left(\mathrm{CT}_{\mathrm{p}}+\mathrm{u}_{\mathrm{p}}{ }^{2} / 2\right)
$$


The force term in the momentum equations of gas and solid phases is:

$\mathrm{F}=\rho_{\mathrm{p}}\left(\mathrm{u}_{\mathrm{g}}-\mathrm{u}_{\mathrm{p}}\right) \mathrm{A}$

The energy term in the energy equations of gas and solid phases is:

$\mathrm{q}=\rho_{\mathrm{p}}\left(\mathrm{T}_{\mathrm{g}}-\mathrm{T}_{\mathrm{p}}\right) \mathrm{B}$

Where the elements $\mathrm{A}$ and $\mathrm{B}$ are:

$$
\begin{aligned}
& \mathrm{A}=\left[\frac{3}{8} \mathrm{C}_{\mathrm{D}}+1.75+\frac{150 \phi}{\mathrm{R}_{\mathrm{e}}}\right]\left[\frac{\rho_{\mathrm{g}}\left|\mathrm{u}_{\mathrm{g}}-\mathrm{u}_{\mathrm{p}}\right|}{\bar{\rho}_{\mathrm{P}} \mathrm{r}_{\mathrm{p}}}\right] \\
& \mathrm{B}=\frac{3}{2} \frac{\mathrm{C}_{\mathrm{p}} \mu \mathrm{N}_{\mathrm{u}}}{\bar{\rho}_{\mathrm{p}} \mathrm{r}_{\mathrm{p}}{ }^{2} \mathrm{P}_{\mathrm{r}}}
\end{aligned}
$$

The gas viscosity $\mu$ is approximated by Sutherland's law:

$\mu=1.71 \times 10^{-5}\left[\frac{\mathrm{T}_{\mathrm{g}}}{273}\right]^{0.73}$

The following equations of drag coefficient $C_{D}$ and the Nusselt number $\mathrm{Nu}$ as given in Ludwig et al. [1997] are valid for $1<\operatorname{Re}<10^{3}$ ];

$$
\begin{aligned}
& C_{D}=(24 / \operatorname{Re})\left[1+0.15 \operatorname{Re}^{0.867}\right] \\
& N u=2+0.7 \operatorname{Re}^{1 / 2} \operatorname{Pr}^{1 / 3}
\end{aligned}
$$

The relative Reynolds number $R e$ is given by:

$$
\mathrm{R}_{\mathrm{e}}=\frac{\rho_{\mathrm{g}}\left(2 \mathrm{r}_{\mathrm{p}}\right)\left|\mathrm{u}_{\mathrm{g}}-\mathrm{u}_{\mathrm{p}}\right|}{\mu}
$$

Where $r_{p}, T_{p}, u_{p}$, and $C$ are the particles radius, temperature, velocity and specific heat, respectively. The gas pressure, temperature, velocity, specific heat at constant volume, the ratio of specific heats and Prandtl number are $p_{g}$, $\mathrm{T}_{\mathrm{g}}, \mathrm{u}_{\mathrm{g}}, \mathrm{C}_{\mathrm{v}}, \gamma, \mathrm{Pr}$, respectively.

Different models for force exchange between phases have been used for different applications in two-phase flow of gas and solid particles. Baer et al. [1986] and Baer [1992] used a correlation obtained by Shepherd and Begeal [1983] as determined from experimental results of shock-induced high speed flow in porous shock tube. Baer et al. [1986] indicated that the inertia forces could be important since the drag coefficient in that model increases with Reynold's number. Sakakita et al. [1992] used Ergun [Bird et al .1960] and Henderson [1976] type of drag coefficients in their numerical study on the interaction between a powder layer and a shock wave. 
In the present work the modification to Ergun model was notified appears in equation (16) by the addition of the term $\left(\frac{3}{8} C_{D}\right)$ in equation (16). The present numerical results showed better comparison with Skews [1991] experimental results when this term is included.

\section{2-5. The Initial and Boundary Conditions:}

It is assumed that the incident shock wave is driven in the tube shown in Fig. 1 by a constant speed piston very far behind in the tube such that wave reflections will not reach the piston face in the computational domain. The computational domain length is $1 \mathrm{~m}$. The shock wave moves from left to right. The gas states behind the incident shock are found from Rankine-Hugoniot reletions based on the incident shock Mach number. In front of the shock, the und:sturbed atmospheric conditions $\left(\mathrm{Tg}=300 \mathrm{~K}\right.$ and $\mathrm{p}_{\mathrm{g}}=83 \mathrm{kPa}$ ) are used. Regarding the boundary conditions, the velocities of particles and gas are zero at the closed right-hand side of the tube end.

\section{3-THE NUMERICAL SOLUTION:}

The governing equations (6-11) in semi-conservative forms, and the gas equation of state (12) with the use of the aforementioned initial and boundary conditions are solved numerically using the second order explicit MacCormack scheme [1969]. The time step is calculated by the well known Courant Friedrich and Lewy stability condition (CFL) using the Courant number $(\lambda)$ as follows:

$$
\Delta t=\frac{\lambda \Delta x}{a_{g}+\left|u_{g}\right|}
$$

Where $\mathrm{a}_{\mathrm{g}}$ and $\mathrm{u}_{\mathrm{g}}$ are the local values of sound speed 'and gas velocity, respectively. The mesh size is $\Delta x$. The Courant number varies from 0.5 to 0.98 based on the incident shock strength. The time step is taken as the minimum value allover the domain at each time level. The flux-corrected transport (FCT) scheme of Book et al. [1975] is used with MacCormack scheme to minimize numerical oscillations. 


\section{4-RESULTS AND DISCUSSION:}

\section{4-1. Comparison with Skews [1991] experimental results:}

It is of great importance, first, to compare the present numerical results, using the aforementioned model, with the experimental results of Skews [1991] in order to make sure that the used model works well. The comparison will be for the cases in which the incident shock Mach number is 1.25 , the foam density $\left(\rho_{\mathrm{f}}\right)$ is $14.8 \mathrm{~kg} / \mathrm{m}^{3}$ and the foam length of $190 \mathrm{~mm}$ and $120 \mathrm{~mm}$. The case of foam length of $50 \mathrm{~mm}$ and incident shock Mach number of 1.27 and foam density of $14.8 \mathrm{~kg} / \mathrm{m}^{3}$ is also used. The initial volume fraction of solid phase is taken 0.05 , as measured by Skews [1991]. The ambient pressure and temperature are $83 \mathrm{kPa}$ and $300 \mathrm{~K}$ as used in Skews experiments. The chosen solid particle radius in the present work is $50 \mu \mathrm{m}$.

Fig. (1) illustrates the tube and locations of pressure records as given in Skews [1991] experiment and also in the present calculations. In Fig. (2a, 2b and $2 \mathrm{c}$ ) a comparison between the present numerical pressure traces (on the left-hand side) with the pressure transducer records of Skews [1991] (on the right-hand side) at locations shown in Fig. (1) is presented. The numbers 1, 2,3 and 4 on the curves designate the locations at which the pressure is traced. Locations 1 and 2 lie in front of the foam slab for the three considered foam lengths. The location 3 coincides exactly with the initial foam face of length $120 \mathrm{~mm}$, and alongside the foam of length $190 \mathrm{~mm}$. The foam length shown in Fig. 1 is $190 \mathrm{~mm}$. The location 4 is at the wall behind the foam.

The process of shock wave interaction with foam occurs as follows: when the incident shock hits the foam face, a shock wave is reflected back into the gas and a transmitted wave propagates through the foam. The latter is reflected off the wall behind the foam to propagate backward through the foam and then emerges from foam/gas interface into the gas.

Generally, the comparison reveals that, the present numerical results reflect, almost all the features recorded by Skews [1991]. The first pressure jump on curves 1 and 2 are due the passage of the incident shock wave over the corresponding locations, while the second jump is due the reflected shock wave at the gas/foam interface. The comparison shows that the reflected shock pressure jump at locations 1 and 2, in all cases, is almost equal that recorded by Skews. For foam length of $12 \mathrm{~cm}$, the location 3 lies exactly at the initial foam/gas interface. Therefore, the shock hits the foam face at that location. Hence, the pressure rises from the undisturbed initial state to that behind the reflected shock wave. In both numerical and experimental records, the rise occurs gradually. For foam length of $19 \mathrm{~cm}$, the location 3 lies alongside the foam. Therefore, the first wave arrives this location is the transmitted wave that is clearly of compression type and has equal strength in both numerical and experimental records.

The transmitted wave propagates into the foam and it is reflected off the solid wall behind the foam to propagate backward and then emerges into the gas through the foam/gas interface as a compression wave. 

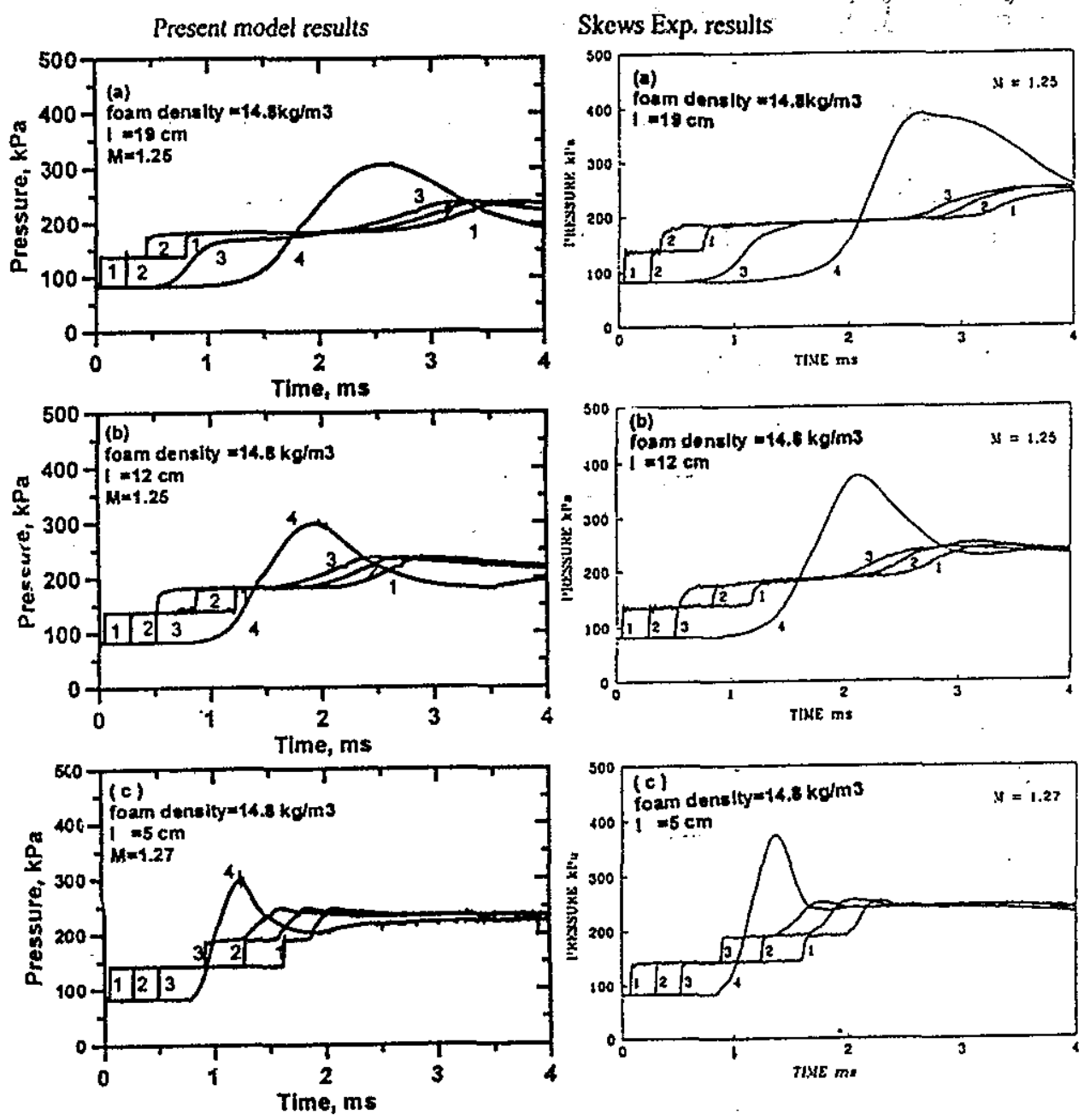

Fig. $(2 a, b, c)$ Comparison of the present calculated pressure histories at locations $1,2,3$ and 4 (on the left) with that experimentally recorded by Skews (1991) (on the right)

This wave arrives to locations 1,2 and 3 , as a gradual pressure rise, after a period of time that depends on its location and the foam slab length. As shown it is significantly. smeared with time. The wave is steeper for shorter foam length. Both numerical and experimental records show similar results as shown in the figure.

The record of pressure at the wall behind the foam (curves labeled 4) shows a gradual increase to a maximum value followed by a decrease and then an increase to almost constant value but it takes longer time to do so as the foam length increases. Even though, the used model is simpler compared with that used by Baer [1992], the comparison with the experimental measurements is fairly good and the used numerical technique is capable of capturing all the 
complex features of the problem. In addition, the used numerical scheme resolved the shock wave accurately and it is very sharp and clean compared with Baer's [1992] results. It is worth to notice that the arrival of the transmitted wave to the wall is a little bit faster in numerical results compared with the experimental one. The reason may be because of the resistance to wave motion in the actual foam skeleton in which the cells are tied together. This will be for sure greater than that of assuming the foam as two-phase mixture of particles suspended in air. Even though, the used model could be a useful tool of predicting the interaction process.

\section{4-2. Spatial and temporal flow field:}

In Fig. ( $3 a, b$ and c) the spatial variation of pressure, velocity and volume fraction of solid phase are plotted for successive time levels. At time $t=0$ the incident shock wave is located at $x=0.06 \mathrm{~m}$ and the foam face at $\mathrm{x}=0.21$ $\mathrm{m}$. The foam slab length is $190 \mathrm{~mm}$, the foam density. is $14.8 \mathrm{~kg} / \mathrm{m}^{3}$ and the incident shock Mach number is 1.25 . The foam initial location is shown as vertical dashed line at $\mathrm{x}=0.21 \mathrm{~m}$.

It is important to point out here that the instantaneous values of solid volume fraction is calculated from the following equation;

$$
\phi=\frac{\rho_{\mathrm{p}}}{\bar{\rho}_{\mathrm{p}}}
$$

Where $\bar{\rho}_{\mathrm{p}}$ is the material density of solid particles that does not change.

The shock initially propägates through the gas until it hits the foam/gas interface. The result of interaction is a reflected shock (FRW) that propagates backward into the gas and a transmitted compression wave (TW) that propagates through the foam. The pressure profiles show that the transmitted wave is smeared over long distance, unlike the reflected wave that is clearly sharp. In addition, the transmitted wave penetrates through the foam with a speed much smaller than that of the reflected shock wave into the gas. Therefore, It could be concluded that the transmitted wave is a compression wave and the reflected wave is a shock wave. In the present case, the calculated speed of propagation of the transmitted wave is almost $43 \mathrm{~m} / \mathrm{s}$ and that of the reflected shock is $82 \mathrm{~m} / \mathrm{s}$. When the transmitted wave head reaches the wall behind the foam, the pressure there grows up gradually with time until it equals the pressure behind the reflected shock wave. Following that the pressure at the wall continues to increase and a second reflected wave (SRW) starts to propagate backward through the foam as depicted in pressure profiles. The pressure increase at the wall is attributed to the compression imparted on the gas adjacent to the wall by the compressed foam and the gas stagnation at the wall. The pressure reaches to a maximum value and then it decreases again when the reflected wave is detached from the wall and starts to propagate backward followed by the gas. This is discerned in the gas velocity profiles shown in Fig. (3b) when the gas near the wall attains negative velocity. 

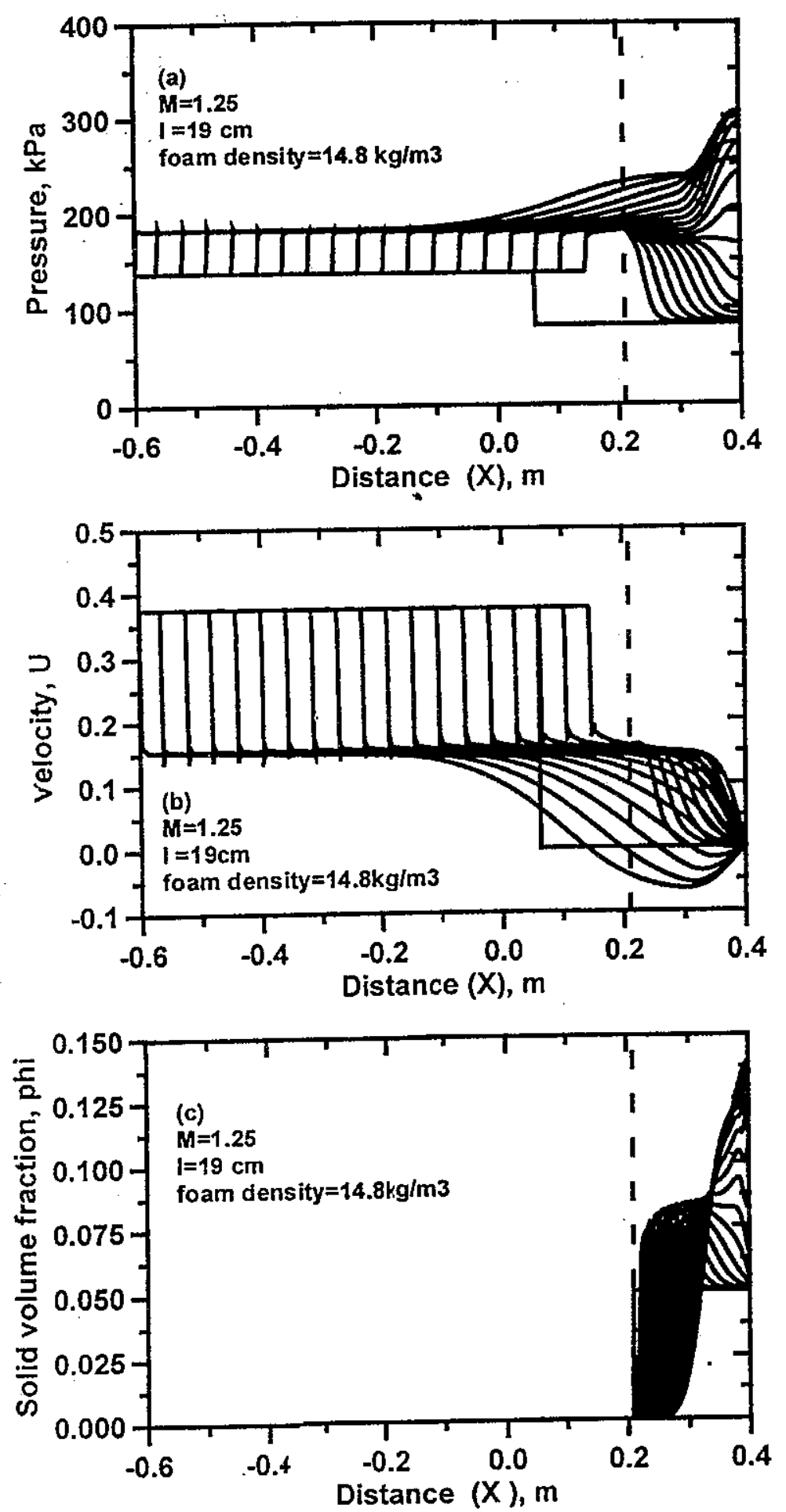

Fig. ( $3 a, b$ and c) Spatial and temporal variation of pressure, gas velocity and solid volume fraction following the impact of incident shock wave with the foam face. 
The profiles of gas velocity (nondimensionalized with the sound speed at the initial gas state) are shown in Fig. (3b). They illustrate the complex wave interaction with foam. The gas velocity behind both the transmitted and reflected wave is decreased significantly as displayed in the figure as soon as the incident shock strikes the foam face. The reflected shock propagating backward increases the pressure and decreases the gas velocity as shown. The results show a plateau, of uniform pressure and velocity, between the reflected shock and the tail of transmitted wave. This situation remains until the second reflected wave (SRW) arrives and causes the pressure to increase and the velocity to decrease as mentioned by Skews [1991].

The foam compression process starts when the incident shock strikes the foam face giving it a momentum to move. The foam face is accelerated initially, as shown in Fig. (3c) and then moves with almost constant velocity of $24 \mathrm{~m} / \mathrm{s}$. The initial acceleration initiates a compaction wave ahead of the foam face that is clearly seen in Fig. (3c). The compression of foam raises the volume fraction of solid phase in the mixture as displayed in the figure. The pressure and solid volume fraction profiles show that the compaction wave head reaches the wall later than the transmitted wave. This indicates that the compression wave precedes the compaction wave, but their propagation speeds are of coniparable magnitude. Fig. (3c) displays the rapid increase in volume fraction of solid phase and the increase rate diminishes when the head of the compaction wave reaches the wall. The volume fraction $\phi$ increases sharply adjacent to the wall and then the foam starts to expand again when the reflected wave is detached from the wall, as mentioned earlier causing the pressure there to decrease as shown in the pressure profiles. The foam slab is compressed from $190 \mathrm{~mm}$ to almost $73 \mathrm{~mm}$.

\section{4-3. Effect of incident shock Mach number:}

The effect of incident shock Mach number on the pressure at wall behind the foam is depicted in Fig. (4). Here the foam slab length is $5 \mathrm{~cm}$ and the foam density is $14.8 \mathrm{~kg} / \mathrm{m}^{3}$. It is noticed that for higher incident Mach number, the corresponding transmitted wave reaches faster to the wall. This means that it is stronger. The maximum wall pressure is greater for greater incident shock Mach number presumably because the foam is compressed more and causes more compression of the gas. One notices also that the rate of pressure increase is greater for greater incident shock Mach number. The wall pressure decreases and then increases to almost constant value depending on the incident shock Mach number. This behavior is noticed experimentally by

Sakakita et al. [1992]. The wall pressure decreases due to the gas expansion behind the reflected wave, as explained previously. The pressure traces at location 3, shown in Fig.(5), illustrate that the strength of the reflected shock wave at foam/gas interface (FRW) and that reflected at the wall (SRW) increases with the increase in incident shock Mach number, as well. 


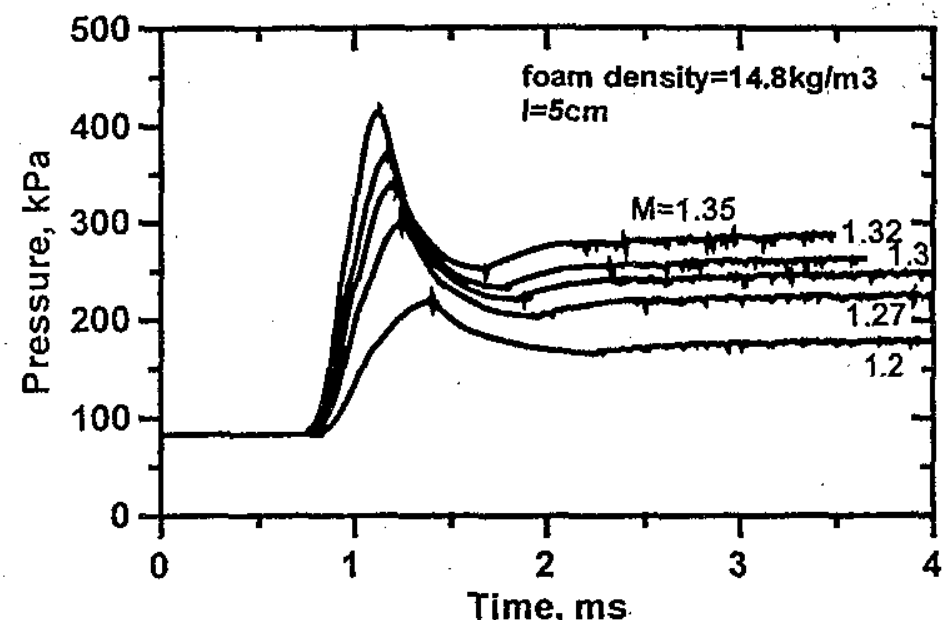

Fig. (4) Effect of incident shock Mach number on the back wall pressure.

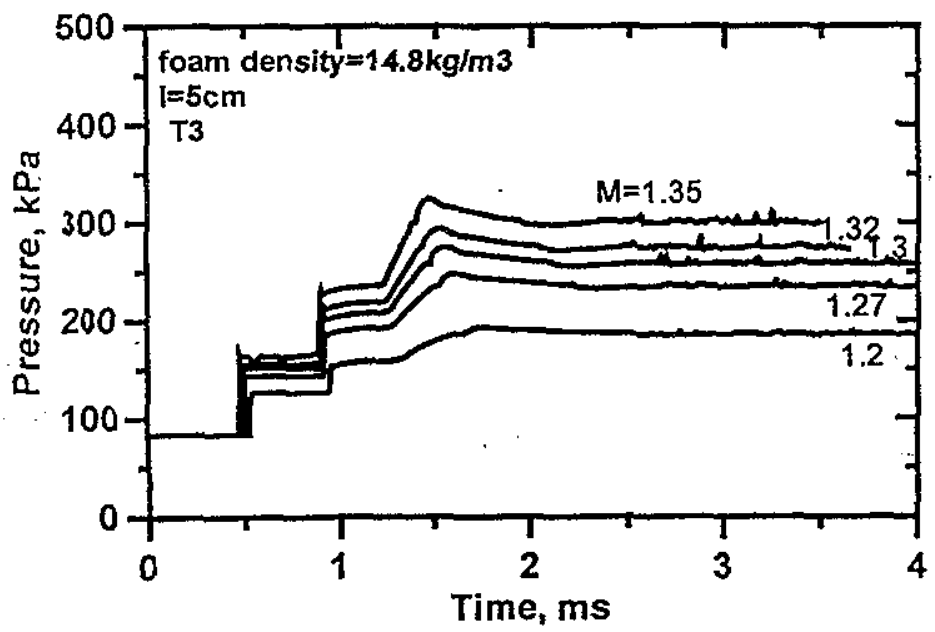

Fig.(5) Pressure traces at location 3 for different incident shock Mach numbers.

\section{4-4. Effect of foam density:}

In Fig. (6) the influence of foam density on the pressure at wall behind the foam is shown. Yere the incident shock Mach number is 1.27 and foam slab length is $5 \mathrm{~cm}$. The foam density is shown on each curve. It is worth to remember here that all the considered foams have equal values of solid volume fraction, as stated earlier. The results indicate that the peak pressure decreases with the increase in foam density. It is seen also that the less the foam density the steeper is the pressure rise at the back wall. The most understandable interpretation of this behavior is that foam with higher density resists the gas motion mere because the material density of skeleton is higher and therefore, it absorbs nore momentum from the gas in order to move. The gas pressure at the back wall decays to almost constant value regardless of the foam density, as could be seen in Fig. (6) at times greater than 3.5. Therefore, it does not depend 
on foam density. Fig. (7) shows the pressure profiles for two values of foam densities; $14.8 \mathrm{~kg} / \mathrm{m}^{3}$ (dashed profile) and $32.5 \mathrm{~kg} / \mathrm{m}^{3}$ (solid profile) for the case in which incident shock Mach number is 1.25 and foam slab length is 19 $\mathrm{cm}$. These profiles are taken at the same time level. It illustrates clearly that the transmitted wave for lower density foam precedes that of the higher density foam. However, the reflected shock wave at the foam face is weaker for small density foam. The transmitted wave speed is almost $43 \mathrm{~m} / \mathrm{s}$ for smaller density foam and almost $32 \mathrm{~m} / \mathrm{s}$ for the greater density foam. The corresponding reflected shock speeds are $82 \mathrm{~m} / \mathrm{s}$ and $90 \mathrm{~m} / \mathrm{s}$, respectively.

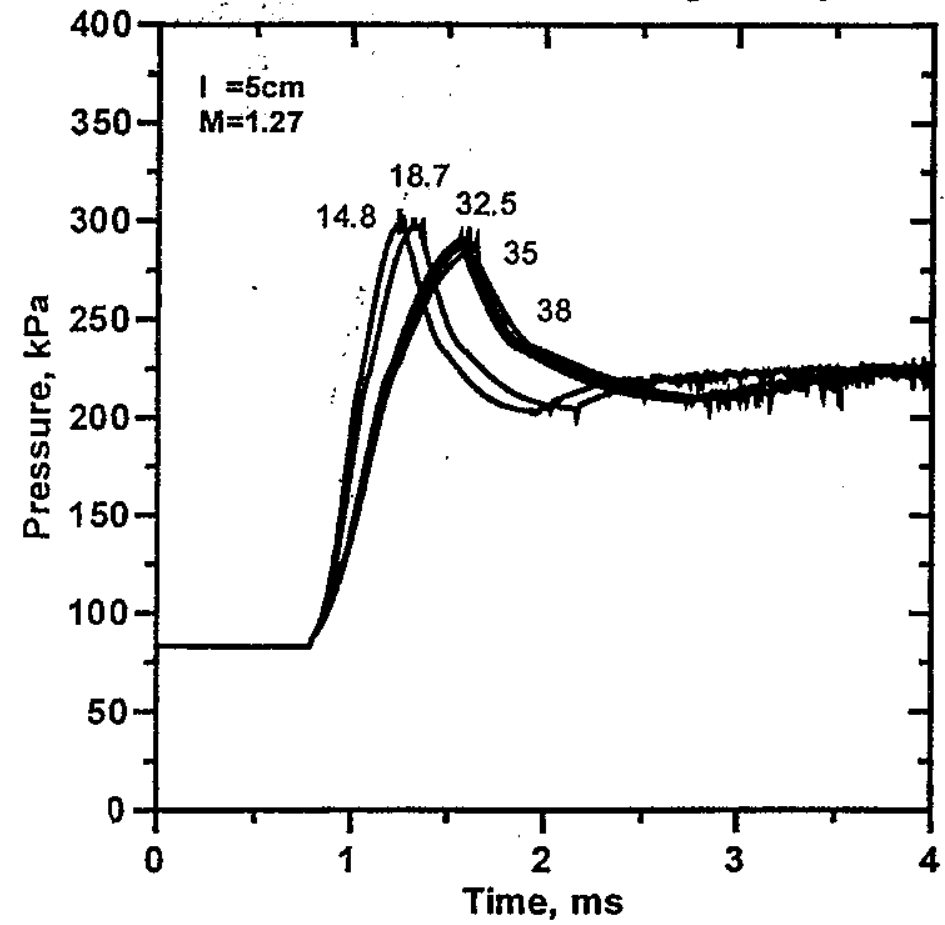

Fig. (6) Effect of foam density on the back wall pressure.

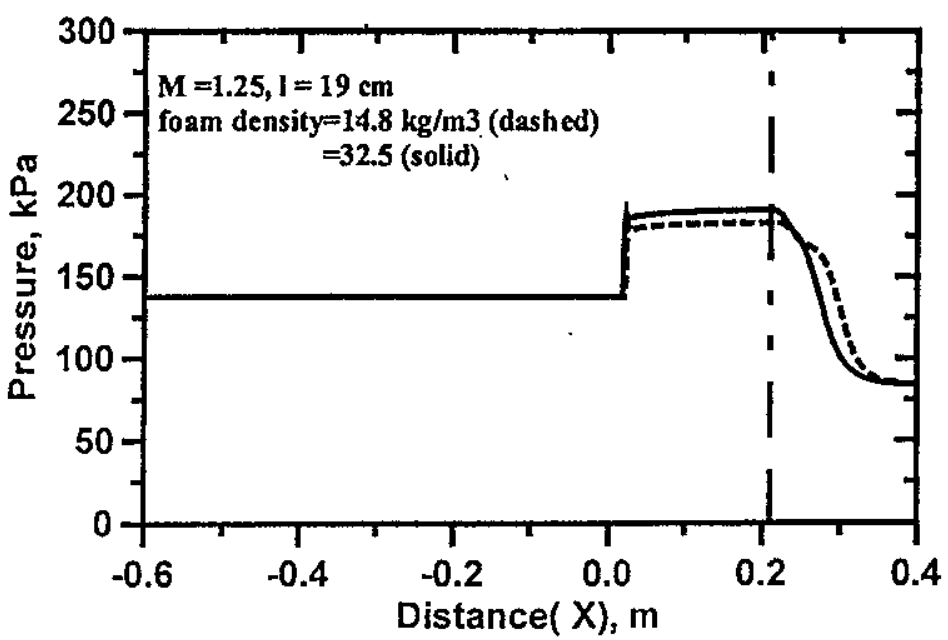

Fig. (7) Effect of foam density on the reflected and transmitted wave speeds. 


\section{4-5. Effect of foam slab length:}

Fig. (8) displays the influence of foam slab length on the pressure at the wall behind the foam. It is clearly seen that the time of arrival of the transmitted wave to the wall increases significantly with the increase in foam slab length. The figure indicates that the maximum pressure at the wall slightly increases with the increase in foam length as mentioned earlier by Govezdeva et al. [1985]. The figure shows also that the rate of pressure rise is steeper for shorter foam. This is because the longer foam takes longer time to reach its maximum compression than the shorter one. As the foam length increases the gas near the wall experiences continuous compression for longer time. Probably this may be the cause of maximum pressure increase with the increase in foam length. The pressure at the wall decreases to almost constant steady value regardless of the foam slab length. Fig. (9) and Fig. (10) are plotted for the pressure and solid volume fraction for foam lengths of $12 \mathrm{~cm}$ and $24 \mathrm{~cm}$, respectively at two successive time levels. In these figures the Mach number of the incident shock is 1.25 and foam density is $14.8 \mathrm{~kg} / \mathrm{m}^{3}$. In addition, the initial distance between the incident shock and the foam face is the same for both foam lengths. The results in these show that the foam slab length has almost no influence on the reflected shock, the transmitted wave, foam face, and compaction wave speeds.

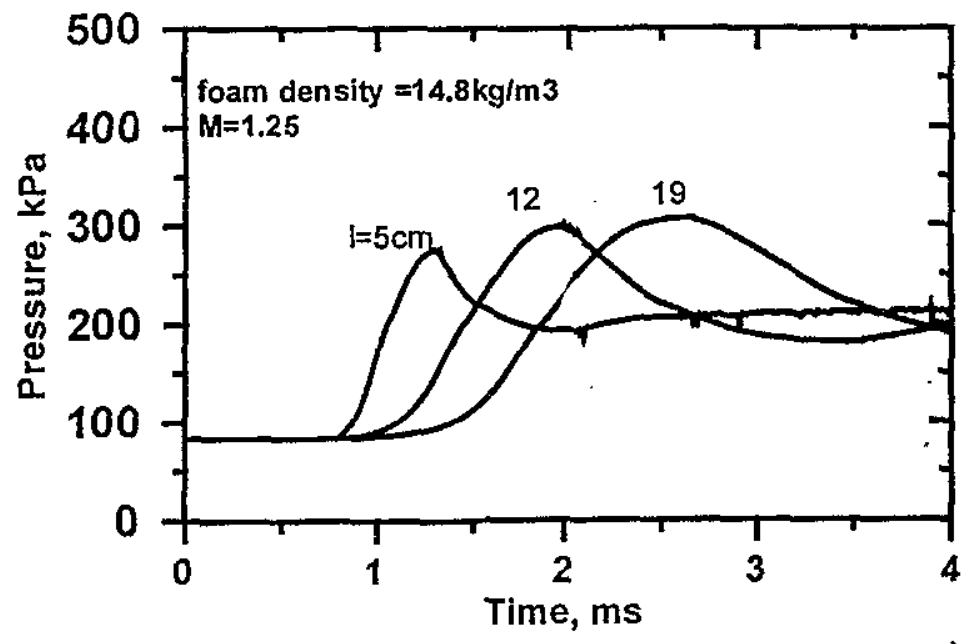

Fig. (8) Effect of foam slab length on the back wall pressure. 


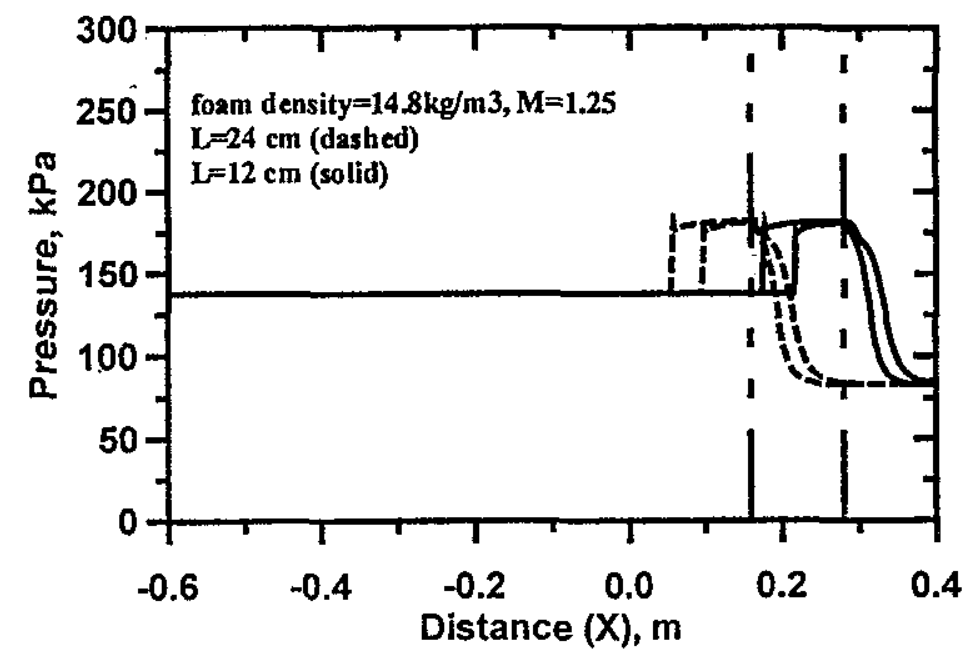

Fig. (9) Effect of foam slab length on reflected and transmitted wave speeds.

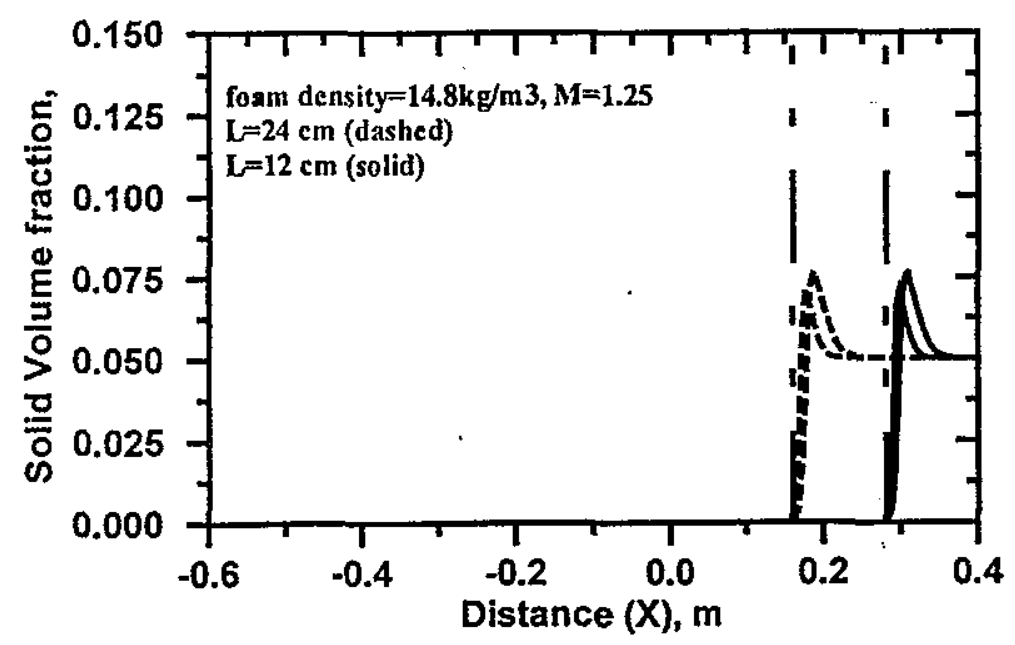

Fig. (10) Effect of foam slab length on foam face and compaction wave speeds.

Fig. (11) shows a comparison between shock wave reflection off solid wall with and without foam (curves with one steep jump) attached to the wall for two values of incident shock Mach number; namely 1.25 (solid curve) and 1.35 (dashed curve). It is seen clearly that the existence of foam causes the pressure at wall to increase appreciably to a maximum value then decreases finally to almost steady state value after long time. This steady value is very close to that without foam. Govezdeva et al. [1985] experimental measurements showed similar results. The peak pressure obtained with foam is almost 25\% higher for incident shock Mach number of 1.25 and almost $40 \%$ for incident shock Mach number of 1.35 . It is notable also that the transmitted wave reaches faster to the wall without foam. 


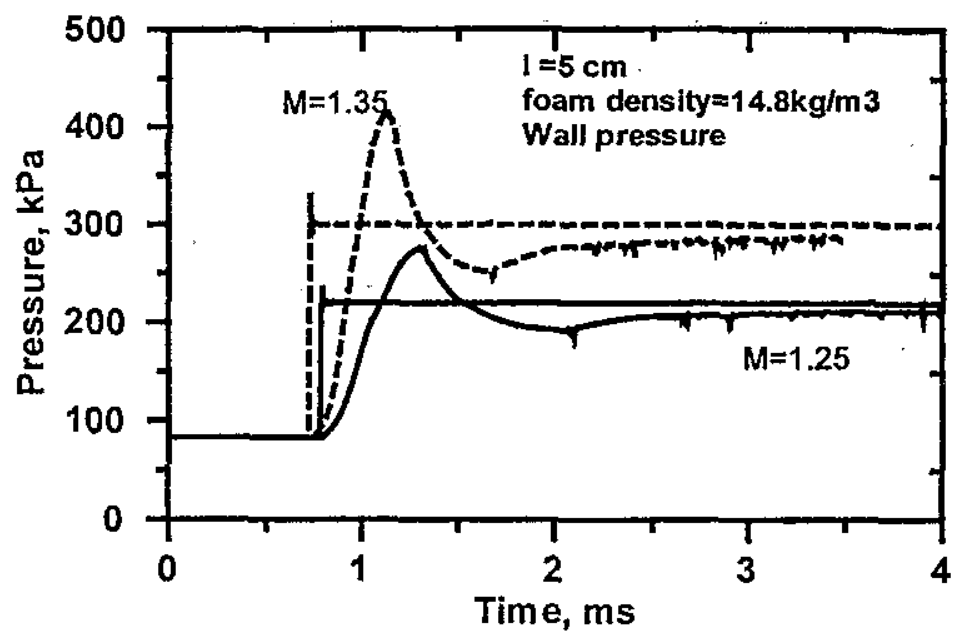

Fig. (11) Comparison between shock wave reflection off solid wall with and without a slab of foam attached to it.

The global analysis of the previous results indicates that the main drop in wave speed occurs at foam/gas interface. The propagating speeds of transmitted, reflected, foam face and compaction waves are almost constant for a certain foam type, length and incident shock Mach number.

\section{5-CONCLUSIONS:}

The present numerical simulation of shock wave interaction with a slab of foam attached to a solid wall showed the capability of the used model to capture all the features measured experimentally by many authors. It is shown that the transmitted wave through the foam is of compression type and that reflected at the gas/foam interface is shock wave. The results show an evidence of formation of compaction wave that propagates through the foam following the impact of the foam face by the incident shock, however, it is preceded by the transmitted gas compression wave. The foam slab is compressed by the incident shock and then it expands when the transmitted wave is reflected off the wall. The maximum wall pressure with foam attached to it exceeds the corresponding value with no foam by a considerable value that depends on the incident shock Mach number, the foam slab length and the foam density. The maximum pressure at wall increases slightly with the increase in foam slab length and decreases with the increase in foam density. The wall pressure decays to almost constant value after reflection and that value depends only on the incident shock Mach number. It could be concluded also that the transmitted wave propagates through the foam with almost constant value for a certain foam type, length and density. 


\section{NOMENCLATURE:}

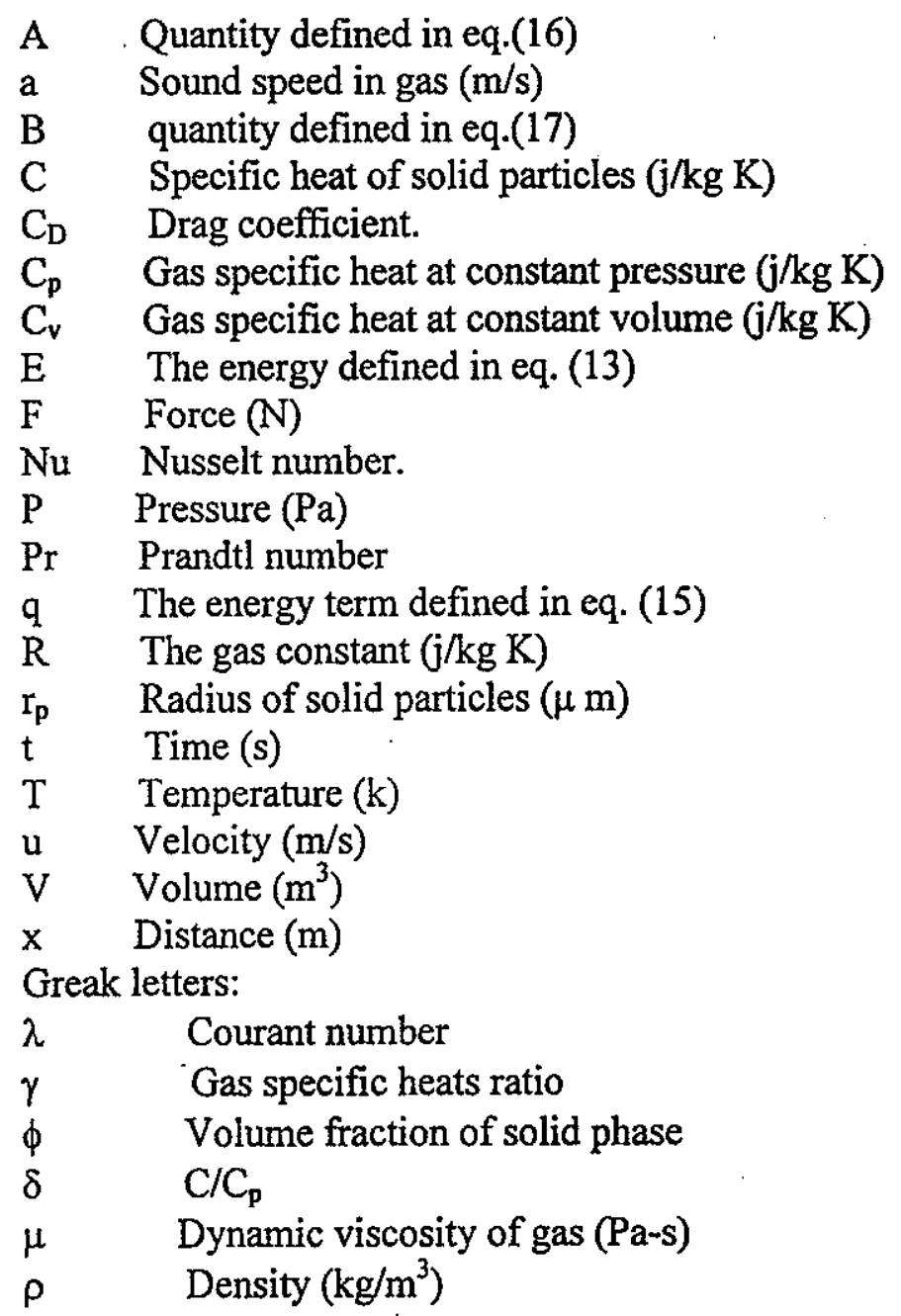

Subscripts:

$\begin{array}{ll}\text { a } & \text { Atmospheric conditions. } \\ \mathrm{f} & \text { Foam material } \\ \mathrm{g} & \text { Gas } \\ \mathrm{p} & \text { Particles }\end{array}$

\section{6-REFERENCES:}

1-B. W. Skews 'The reflected pressure field in the interaction of weak shock waves with a compressible foam' Shock Waves (1991) 1:205-211 2-Rodolfo Monti (1970) 'Normal shock wave reflection on deformabel solid walls' Meccanica 4:285-296 
3-Gelfand BE, Gubin SA, Kogarko SM and Popov OE (1975)' Investigation of propagation and reflection of pressure waves in porous media $\mathrm{Zh}$ Prikl Mekh Fiz 16(6):74-77

4-Gelfand BE, Gubonov AV and Timofeev EJ (1983)' Interaction of shock wave in air with a porous screen' Izvestiya Akademii Nauk SSSR Mekhanika Zhidkostii Gaza 4:78-84

5-Kamel, M. M., and abdulraouf (1984) 'Current status of blast wave theory and computations' Vol. II, Europian research office, United States Army.

6-Gvozdeva, L. G., Faresov Y. M., Brossard J and Charpentier N Normal shock reflection on porous compressible material $10^{\text {th }}$ ICDERS, Berkeley, U. S. A., 1985

7-El-Mokkadem A. E., El-salamoni M. A., Elieche A. M. and Kamel M. M." Study of the damping capacity of foam materials against detonation pressure waves" The $1^{\text {st }}$ Conference of the Egyptian combustion society. The higher technological institute, Ramadan tenth city, Egypt, Dec. 26-28, 1989, pp.117139.

8-B. W. Skews, M. D. Atkins and M. W. Seitz 'The Impact of a Shock Wave on Porous Compressible Foams' J. Fluid Mech.(1993), Vol. 253, pp.245-265

9-M. R. Baer (1992) 'A numerical study of shock wave reflections on low density foam' Shock Waves 2:121-i24

10-M. R. Baer and J. E. Nunziato (1986) ' A two-phase mixture theory for the deflagration -to-detonation transition (DDT) in reactive granular materials' Int. J. Multiphase flow Vol.12, No.6, pp.861-889

11-Hajime Sakakita and A. K. Hayashi 'Study on the interaction between a powder layer and a shock wave' $18^{\text {th }}$. Int. Symp. on Space Tech. and Science, May 17-23, 1992, Kagoshima.

12-Ahmed A. Sileem ' Initiation and propagation of detonation wave in twophase mixture of reactive gas and inert solid particles' Proceedings of the $11^{\text {th }}$ International Mechanical Power Engineering Conference. Cairo, Egypt, Feb.(57) 2000 , vol. 1 , pp. C112-C126

13-T. Ludwig and P. Roth' Modeling of Laminar Combustion Wave Propagation in Reactive Gas/Particle Mixtures' Int. J. Multiphase Flow, Vol. 23, No. 1, pp.93-111, 1997.

14- K. A. Ibrahim (1983) 'Interaction of a shock wave with a right angled bend in two-phase flow' Eng. Res. Bull., Faculty of Eng., Menoufia University, Vol. $\mathrm{V}$, Part 1, p 219.

15-R. W. MacCormack The Effect of Viscosity in Hypervelocity Impact Cratering`AIAA Paper 69-354, Cincinnati, Ohio, U.S.A., 1969.

16-Book, D. L., Bories, J. P. and Hain, K. (1975) 'Flux-corrected transport II: Generation of the method' J. Comput. Phys. 8, pp. 248-283. 
نـــمذجه عددية للتأثير المتبادل بين صدمة عموديه مع لوح

من الإسفنج ملتصق بجدار صلب

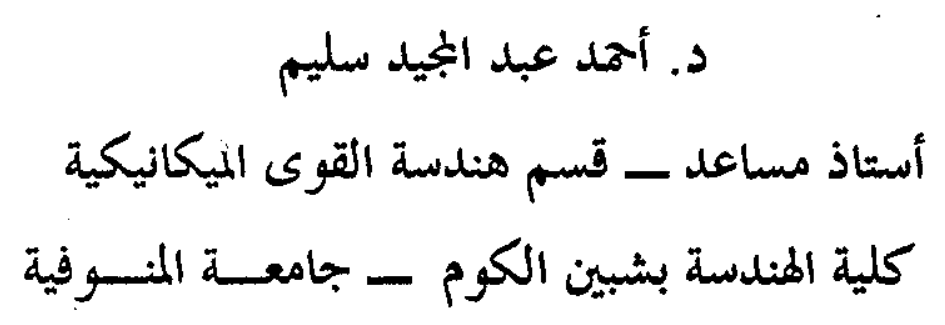

في هذا البحث تم عمل نغوذج نظرى لدراسة التأئي المتبادل بين صدمه عموديسه.

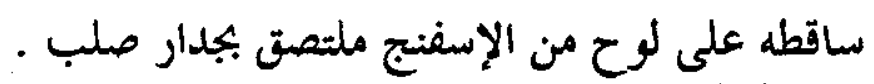

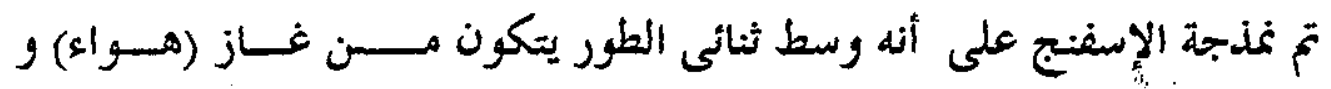

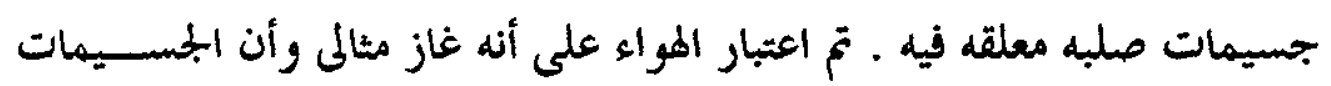

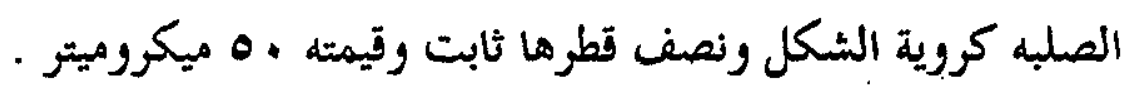

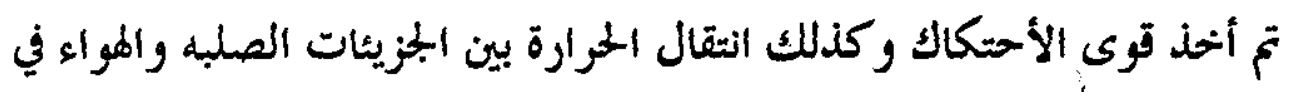
الاعتبار عند سريان الصدمه في الإسفنج · تع حل المعادلات الحاكمة للستسريان ثنائى الطور عدديا . تع دراسة تأثير كثافة الإسفنج ورقم ماخ للصلمه الساقطه وطول عينة الإسفنج

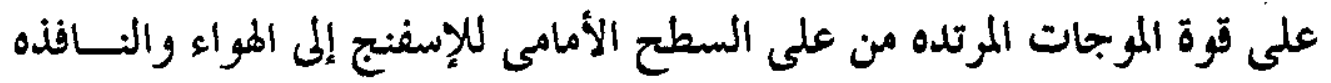

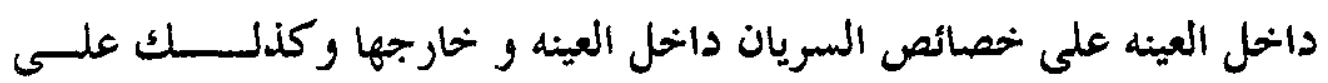
الضغط على الجمدار الصلب خحلف العينه .

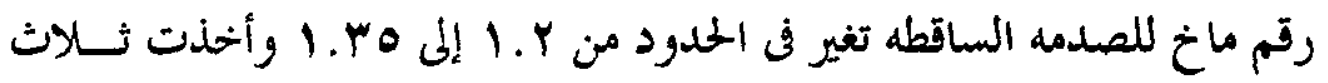

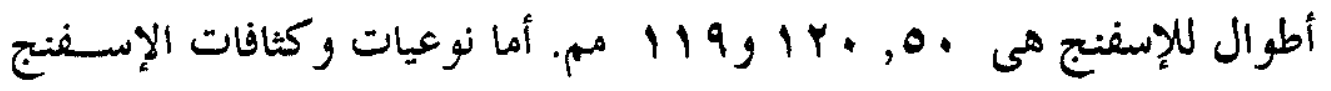
فهى موضحه بالجلدول (I ) داخل البحث . 
أظهرنت نتائج البحث أنه عند ثبوت كل المتغيرات فأن زياده طول العينه يـؤدى إلى تأخر وصول الموجه التافذه إلى الجلدار وأن أقصى أرتفاع للضغط على المئل المدار

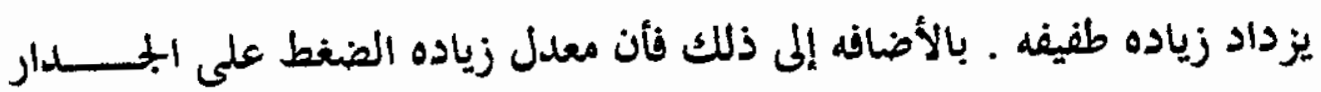

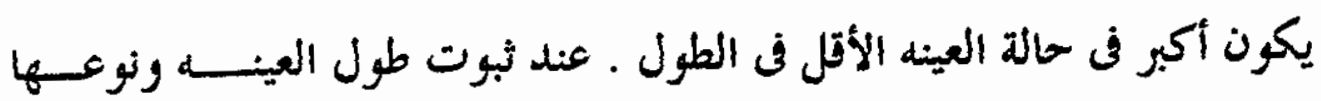

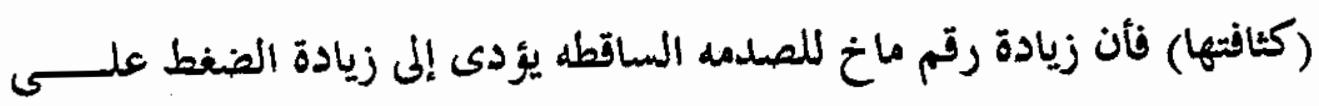

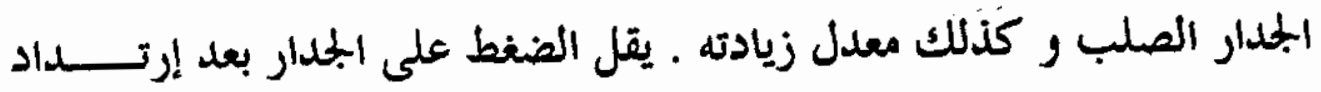

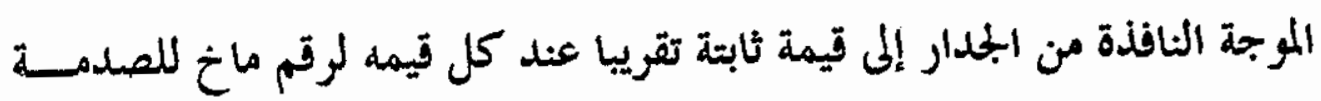

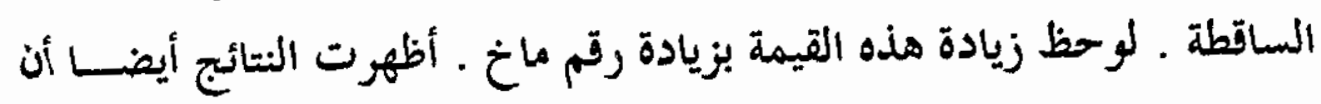

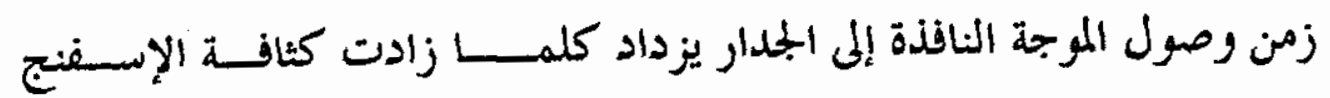

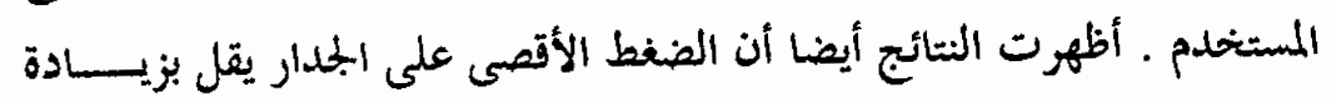

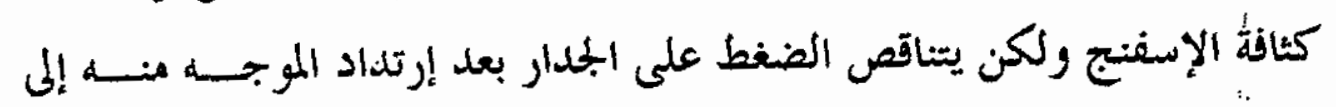
قيمه ثنابته تقريبا بغض النظر عن كثافة الإسفنج .

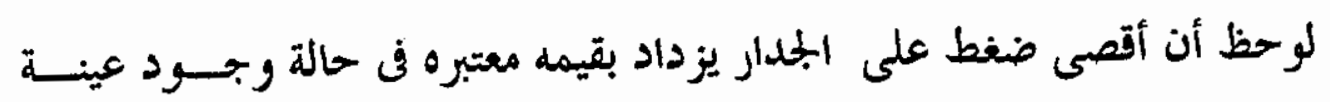
الإسفنج عنه في حالة عدم وجودها لنفس قيمة رقم ماخ للصدمه الساقطه .

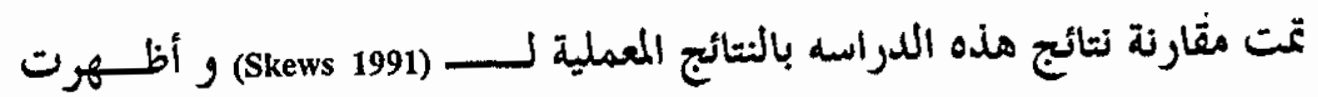

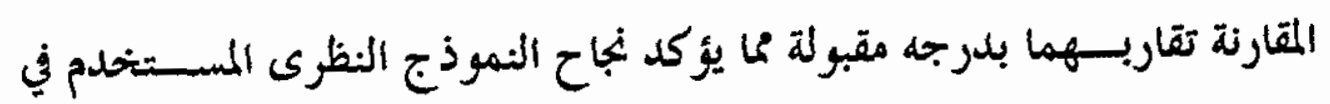
هذه الدراسة في إظهار الملامح الاساسيسه للثأثير المتبادل بين حدمه عموديسه و

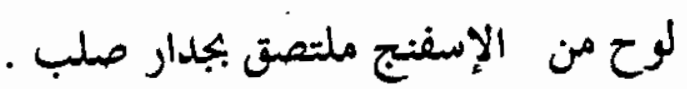

